\title{
Epidemiological, Clinical, and Biochemical Study of Endemic Dental and Skeletal Fluorosis in Punjab
}

\author{
S. S. JOLLY,* M.D., M.R.C.P. ; B. M. SINGH,† M.D. ; O. C. MATHUR, $\ddagger$ PH.D.; K. C. MALHOTRA, M.D.
}

\begin{abstract}
Summary : The incidence of dental fluorosis in 46,000 $\checkmark$ children in the Punjab was assessed and compared with the fluoride content of their water supplies. Ten villages were selected for more detailed studies of skeletal as well as dental fluorosis.

Factors other than the fluoride content of the drinking water which were found to influence the incidence and the severity of fluorosis were the chemical composition of the water and in particular its calcium content; the duration of cxposure; sex and occupation; nutritional status ; and climatic and geological variations. The role of fluoride-containing foodstuffs has yet to be assessed.
\end{abstract}

\section{Introduction}

The Department of Medicine, Medical College, Patiala, has been actively engaged in the epidemiological, clinical, and biochemical studies of endemic fluorosis for the past nine years. These studies have been carried out in Punjab, which is one of the most highly endemic areas in the world. Extensive data on dental, skeletal, and neurological aspects of fluorosis have been collected and fully reported (Singh and Jolly, 1961a; Singh et al., 1961, 1962a, 1963). The object of the present communication is to evaluate the role of various factors causing fluoride toxicity. Even with identical levels of fluoride in the water, the incidence of fluoride intoxication varies, thus clearly pointing to the existence of factors other than the concentration of fluoride.

\section{Material and Methods}

An epidemiological survey to determine the incidence of dental fluorosis was carried out in 358 villages in Punjab. Children aged 5 to 17 years were examined for dental mottling and characteristic dental pigmentation.

Apart from this dental survey, 10 villages from the endemic fluorotic area of Punjab with different fluoride concentrations in drinking-water were selected to assess the effect of various factors on fluoride intoxication. Children and adults (both males and females) of these villages were subjected to thorough clinical and radiological examination. Interosseous membrane calcification was taken as a definite radiological index of skeletal fluorosis.

The waters of these 10 villages were analysed for various important chemical constituents such as total hardness, calcium and magnesium hardness, and alkalinity. In Indian villages there is no regular central water supply. Almost each house has its own hand pump, and the fluoride concentration of the water shows a wide variation in the same village because of the different depths of the wells. Moreover, the farmers and labourers (the subjects of this study) work in the fields away

* Professor of Medicine.

$\dagger$ Research Officer, I.C.M.R.

¥ Research Officer, I.C.M.R.

$\$$ Senior Lecturer in Medicine.

Government Medical College, Patiala, Punjab, India. from the villages and ingest water from different places. It is therefore not possible to evaluate precisely the incidence of fluorosis according to a particular concentration of fluoride in the sample of water. However, the mean fluoride concentration of all water supplies was taken for the purpose of determining the incidence of fluorosis.

\section{Observations}

About 46,000 children were examined in 358 villages in Punjab. The incidence of dental involvement as correlated to fluoride concentration is shown in Table I. The incidence of dental fluorosis was found to rise with increasing fluoride concentration, but there was no rigid linear relationship between fluoride concentration and the incidence of dental involvement. The incidence of dental mottling in children and adults in the 10 villages chosen for special study is given in Table II.

\begin{tabular}{|c|c|c|}
\hline $\begin{array}{l}\text { No. of } \\
\text { Villages }\end{array}$ & $\begin{array}{l}\text { Maximum Concentration } \\
\text { of Water Fluoride } \\
\text { (p.p.m.) }\end{array}$ & $\begin{array}{l}\text { Incidence of Dental } \\
\text { Mottling } \\
(\%)\end{array}$ \\
\hline $\begin{array}{r}210 \\
96 \\
52\end{array}$ & $\begin{array}{r}1 \cdot 4 \\
2 \cdot 3 \\
>2 \cdot 3\end{array}$ & $\begin{array}{r}0-10 \\
10-30 \\
>30\end{array}$ \\
\hline
\end{tabular}

\begin{tabular}{|c|c|c|c|c|}
\hline \multirow{2}{*}{\multicolumn{2}{|c|}{ Village }} & \multirow{2}{*}{$\left|\begin{array}{c}\text { Fluoride } \\
\text { Concentration } \\
\text { (Mean) (p.p.m.) }\end{array}\right|$} & \multicolumn{2}{|c|}{ Incidence of Dental Mottling (\%) } \\
\hline & & & Children & Adults \\
\hline $\begin{array}{l}\text { Gharachaon } \\
\text { Laluwala }\end{array}$. & $\begin{array}{l}\because \\
\because \\
\because \\
\because \\
\because \\
\therefore \\
\therefore \\
\therefore\end{array}$ & $\begin{array}{l}1 \cdot 4 \\
2 \cdot 4 \\
3 \cdot 0 \\
3 \cdot 0 \\
3 \cdot 3 \\
3 \cdot 3 \\
3 \cdot 6 \\
5 \cdot 0 \\
8 \cdot 5 \\
9 \cdot 7\end{array}$ & $\begin{array}{l}22.6(124) \\
30.6(49) \\
24.5(57) \\
55.9(34) \\
47.0(133) \\
53.4(146) \\
27.4(317) \\
52.7(93) \\
81.4(43) \\
66.0(50)\end{array}$ & $\begin{array}{l}13 \cdot 8(87) \\
60 \cdot 2(74) \\
47 \cdot 6(107) \\
31 \cdot 2(64) \\
10 \cdot 0(160) \\
52.5(160) \\
49 \cdot 4(154) \\
56.6(90) \\
55 \cdot 6(58) \\
70.7(232)\end{array}$ \\
\hline
\end{tabular}

Figures in parentheses denote the number of cases.

\section{Skeletal Fluorosis}

The skeletal changes of fluorosis are best described under the headings of gross changes in the skeleton, radiological changes, the chemical composition of bones, the histopathology, and deformities. These changes have been described in detail elsewhere (Singh et al., 1962b). However, the skeletal fluorosis may be completely asymptomatic in the early stages, and the only method of detecting it earlier is by radiological study. Later on it may lead to generalized bone pains, particularly in the spine and joints, and also result in exostosis and deformities such as kyphosis, flexion deformity of the knees, etc. An attempt was made to correlate the incidence of skeletal fluorosis with water fluoride concentration. For this purpose an extensive survey was carried out in the 10 villages. The results are shown in Table III. 
TABLE III.-Incidence of Skeletal Fluorosis

\begin{tabular}{|c|c|c|c|c|}
\hline \multirow{2}{*}{ Village } & \multicolumn{2}{|c|}{$\begin{array}{l}\text { Concentration of } \\
\text { Fluoride in Water (p.p.m.) }\end{array}$} & \multirow{2}{*}{$\begin{array}{c}\text { Incidence } \\
\text { of } \\
\text { Skeletal } \\
\text { Fluorosis (\%) }\end{array}$} & \multirow{2}{*}{$\begin{array}{l}\text { Crippling } \\
\text { Fluorosis }\end{array}$} \\
\hline & Mean & Range & & \\
\hline 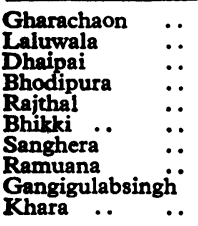 & $\begin{array}{l}1 \cdot 4 \\
2 \cdot 4 \\
3 \cdot 0 \\
3.0 \\
3.3 \\
3.3 \\
3.6 \\
5 \cdot 0 \\
8 \cdot 5 \\
9 \cdot 7\end{array}$ & $\begin{array}{l}0 \cdot 9-2 \cdot 5 \\
1 \cdot 0-5 \cdot 5 \\
1 \cdot 1-5 \cdot 5 \\
1 \cdot 3-5 \cdot 2 \\
0 \cdot 5-6 \cdot 5 \\
1 \cdot 0-5 \cdot 9 \\
1 \cdot 1-5 \cdot 8 \\
1 \cdot 5-11 \cdot 5 \\
3 \cdot 7-14 \cdot 0 \\
6 \cdot 0-16 \cdot 2\end{array}$ & $\begin{array}{l}2.4(82) \\
23.0(74) \\
19.6(107) \\
42.2(64) \\
10.0(160) \\
45.6(160) \\
33.1(154) \\
60.0(90) \\
58.9(56) \\
70.7(232)\end{array}$ & $\begin{array}{l}\text { Negative } \\
\text { Negative } \\
\text { Negative } \\
\text { Positive } \\
\text { Negative } \\
\text { Positive } \\
\text { Positive } \\
\text { Positive } \\
\text { Positive } \\
\text { Positive }\end{array}$ \\
\hline
\end{tabular}

The incidence of skeletal fluorosis was practically nil at a mean concentration of 1.4 p.p.m. but rises with the increase of fluoride concentration in water. The concentration of fluoride alone is not responsible for the incidence of skeletal fluorosis. Thus crippling fluorosis was evident in a village with a mean fluoride concentration of 3 p.p.m., but in another village with the same concentration it did not occur.

\section{Neurological Manifestations of Fluorosis}

In our earlier studies it was reported that in some cases of skeletal fluorosis the neurological complications of radiculomyelopathy occur owing to compression of the spinal cord and roots as a result of irregular bone deposition in and around the spinal canal. This has been convincingly shown in a macerated skeleton (Singh et al., 1962b). So far we have studied 62 proved cases of skeletal fluorosis with neurological manifestations. This is the largest published series. The details of neurological manifestations are being compiled separately, but a summary is shown in Table IV. It is worth emphasizing that only five cases of neurological fluorosis were seen in women against 57 in men.

\section{Factors Influencing Toxicity}

\section{Concentration of Fluoride}

It is generally agreed that fluoride ingestion produces toxic effects, but the concentration which may have deleterious effects is a subject of controversy. The minimal threshold has not
TABLE IV. - Summary of 62 Cases with Neurological Manifestations

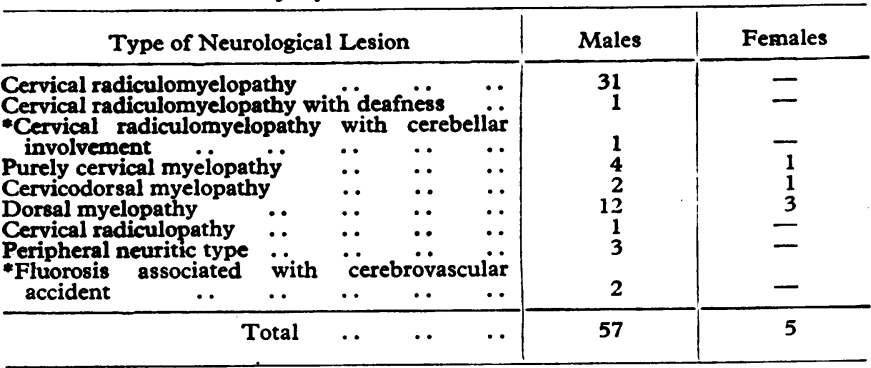

* These cases were probably due to compression of the vertebral artery as it passed through the cervical spine.

yet been definitely established. In some studies from India lower concentrations of fluoride have been shown to be associated with well-marked fluorosis. The present survey shows that concentrations of fluoride from 0.9 to 2.5 p.p.m. are associated with an incidence of only $2.4 \%$ skeletal fluorosis, but that crippling fluorosis was seen in some villages in which the fluoride range was 1.3 to 5.2 p.p.m. The belief that the incidence of skeletal fluorosis is dependent only on the fluoride concentration is shown to be fallacious when two villages, Rajthal and Bhikki, are compared. These villages have practically the same fluoride concentration but show a marked difference in the incidence of skeletal fluorosis. In Bhikki a large number of cases of crippling fluorosis were observed, but not a single similar case was detected from Rajthalclearly showing the existence of factors other than fluoride concentration.

\section{Duration of Fluoride Exposure}

The period of fluoride intoxication has a definite influence on the development of endemic fluorosis, because with a similar fluoride concentration the incidence was found to increase with age. In villages having a low fluoride concentration skeletal fluorosis was detected in an older age group than in villages with a high fluoride concentration.

\section{Sex and Occupation}

Sex and occupation also have some influence on the development of endemic fluorosis, particularly in relation to severe

TABLE V.-Chemical Constituents of Water

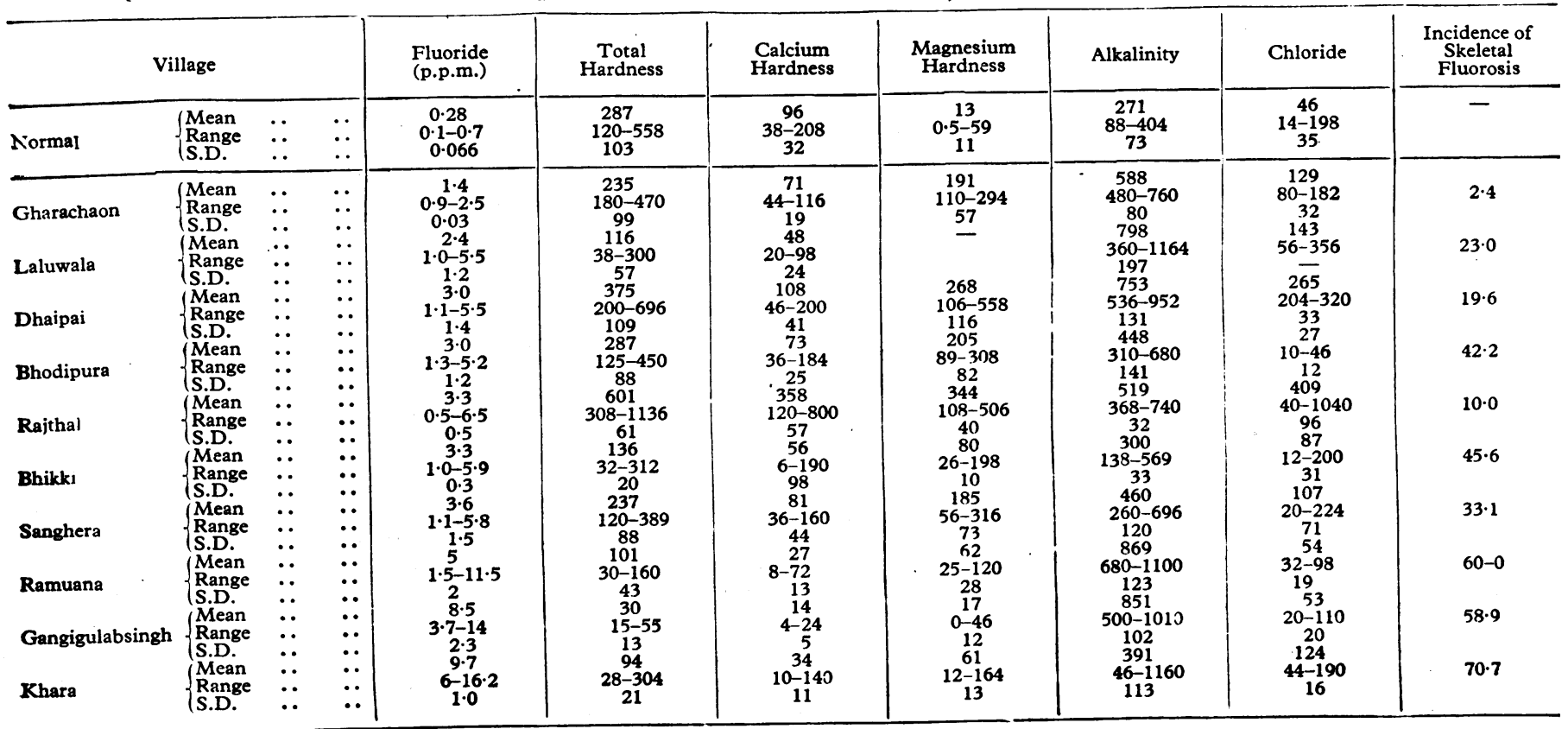


varieties, such as neurological and crippling fluorosis, because there were only five female as compared with 57 male cases. of neurological fluorosis admitted to hospital. T'he disease was far more common in labourers and farmers who do hard manual work and carry heavy loads on the head; this perhaps is one of the factors accounting for a severe type of disease in men and the high incidence of neurological and crippling fluorosis.

\section{Chemical Composition of Water}

Besides the fluoride content, a number of other constituents in water are important, such as calcium, magnesium, and alkalinity. We found that fluoride concentration bears an inverse relation to total hardness and calcium hardness. In areas having low fluoride content the water was harder. The incidence of endemic fluorosis depended to a great extent on the hardness of water. This point was nicely illustrated by comparing the analysis of water constituents from the villages of Bhikki and Rajthal (Table V). In these two villages the water has the same fluoride content but the incidence of endemic fluorosis varies widely. The other factors-nutritional status, climatic effect, duration of fluoride exposure, sex, profession, etc.-were identical ; the only difference was in calcium hardness and magnesium hardness.

In America most of the water containing fluoride is hard water and the fluoride/hardness ratio is more than 1 in 500 , but in our study the fluoride/hardness ratio was much less (Table VI). It is therefore clear that both the calcium and the magnesium content have a protective influence on the absorption of fluoride and its subsequent deposition in the skeleton (Marier et al., 1963). In India the lower toxic limits of fluoride may be related to water that is less hard, as shown in the analysis of water constituents in some of the endemic areas.

\begin{tabular}{|c|c|c|c|c|c|}
\hline \multicolumn{2}{|l|}{ Village } & \multirow{2}{*}{$\begin{array}{c}\begin{array}{c}F: \text { Total } \\
\text { Hardness }\end{array} \\
1: 1025\end{array}$} & \multirow{2}{*}{$\begin{array}{c}\begin{array}{c}\mathrm{F}: \mathrm{Ca} \\
\text { Hardness }\end{array} \\
1: 340\end{array}$} & \multirow{2}{*}{$\frac{F: \text { Alkalinity }}{1: 97}$} & \multirow{2}{*}{$\frac{\mathrm{Ca}: \text { Alkalinity }}{1: 2 \cdot 8}$} \\
\hline Normal & . & & & & \\
\hline 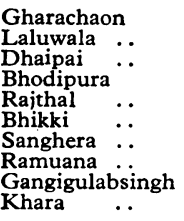 & $\begin{array}{l}\because \\
\because \\
\therefore \\
\therefore \\
\therefore \\
\therefore \\
\therefore\end{array}$ & $\begin{array}{ll}1 & : 167 \cdot 8 \\
1 & : 48 \\
1 & : 125 \\
1 & : 96 \\
1 & 182 \\
1 & : 41 \\
1 & : 66 \\
1 & : 20 \\
1 & : 4 \\
1 & : 10\end{array}$ & $\begin{array}{l:l}1 & : 51 \\
1 & : 20 \\
1 & : 36 \\
1 & : 24 \\
1 & : 108 \\
1 & : 17 \\
1 & : 22 \\
1 & : 5 \\
1 & : 2 \\
1 & : 3\end{array}$ & $\begin{array}{l:l}1 & : 420 \\
1 & : 332 \\
1 & : 251 \\
1 & : 162 \\
1 & : 159 \\
1 & : 91 \\
1 & : 128 \\
1 & : 194 \\
1 & : 101 \\
1 & : 40\end{array}$ & $\begin{array}{l:l}1 & : 8 \cdot 2 \\
1 & : 16 \cdot 6 \\
1 & : 6 \cdot 9 \\
1 & : 6 \cdot 6 \\
1 & : 1 \cdot 4 \\
1 & : 6 \cdot 4 \\
1 & : 5 \cdot 6 \\
1 & : 32 \cdot 1 \\
1 & : 60 \\
1 & : 11 \cdot 5\end{array}$ \\
\hline
\end{tabular}

\section{Nutritional Status}

It has been alleged that the higher incidence of endemic fluorosis in India is partly related to malnutrition, because no case of fluorosis has been detected in other parts of the world with a similar fluoride concentration-for example, Texas (Leone et al., 1954). Our studies in Punjab have not borne this out, because that State is the best-nourished area in India and yet has the highest incidence of fluorosis. However, this needs further elucidation. It has recently been shown by calcium balance studies (Srikantia and Siddiqui, 1965) that cases of fluorosis retain larger amounts of fluoride, and this increased retention is due to lower excretion both in the urine and in the faeces.

\section{Climatic and Geological Factors}

Cases of endemic fluorosis were observed only from those areas where the soil was sandy and the climate was hot and dry. The average temperature during summer was above $100^{\circ} \mathrm{F}$. $\left(37.8^{\circ}\right.$ C. $)$ and the rainfall was rather scanty. Moreover, cases of fluorosis were observed only in those villages where the subsoil water was rather superficial. In deeper wells the fluoride concentration of water was not so high; this has been suggested to be a preventive factor.

\section{Fluoride from Food and Beverages}

Besides the fluoride ingested in drinking-water, considerable quantities of fluoride may be ingested from foods grown in soil rich in fluoride, from tea, and from wines (Soriano and Manchón, 1966). We have still not precisely evaluated these factors in our endemic areas, but it is quite possible that they may aggravate fluoride intoxication, because the villager of Punjab consumes a great deal of tea and alcoholic drinks.

\section{Method for Fluoride Estimation in Water}

\section{Reagents}

Standard Sodium Fluoride Solution.-Dissolve 0.221 g. of sodium fluoride in distilled water and dilute to $1,000 \mathrm{ml}$. Dilute $100 \mathrm{ml}$. of this stock solution to $1,000 \mathrm{ml}$. with distilled water; $1 \mathrm{ml}$. is equivalent to $0.01 \mathrm{mg}$. of fluoride.

Zirconium Alizarin Solution.-Dissolve $0.3 \mathrm{~g}$. of zirconium oxychloride octahydrate in $50 \mathrm{ml}$. of distilled water in a one-litre glassstoppered flask. Dissolve $0.07 \mathrm{~g}$. of sodium alizarin monosulphonate (alizarin red S) in $50 \mathrm{ml}$. of distilled water and pour slowly into the zirconium solution while stirring. The resulting solution clears on standing for a few minutes.

Mixed Acid Solution: Dilute $101 \mathrm{ml}$. concentrated $\mathrm{HCl}$ to $400 \mathrm{ml}$. with distilled water. Add carefully $33.3 \mathrm{ml}$. concentrated $\mathrm{H}_{2} \mathrm{SO}_{4}$ to $400 \mathrm{ml}$. of distilled water. After cooling, mix the two acids.

Acid Zirconium Alizarin Reagent.-To the clear zirconium alizarin solution in the one-litre flask add the mixed acid solution, add distilled water up to mark of one litre, and mix. The reagent changes in colour from red to yellow within an hour and is then ready for use. If stored away from direct sunlight the reagent is stable for at least six months.

Sodium Arsenite Solution.-Dissolve $5 \mathrm{~g}$. of sodium arsenite and dilute to 1 litre with distilled water.

\section{Procedure}

Sample Pretreatment.-If the sample contains residual chlorine, remove it by adding 1 drop $(0.05 \mathrm{ml}$.) of arsenite for each $0.1 \mathrm{mg}$. of chloride and mix.

Preparations of Standards.-Prepare a series of standards by diluting various volumes of standard fluoride solution $(1 \mathrm{ml}=$ $0.01 \mathrm{mg}$. of fluoride) to $100 \mathrm{ml}$. in Nessler tubes. The standards should be chosen so that there is at least one with lower and one with higher fluoride concentration than the unknown sample. An interval of $0.05 \mathrm{mg} . / \mathrm{l}$. is usually sufficient.

Colour Development.-Adjust the temperature of samples and standards so that the deviation between them is no more than $2^{\circ} \mathrm{C}$. A temperature near that of the room is satisfactory. A constant temperature should be maintained throughout the determination. To $100 \mathrm{ml}$. of the clear sample or an aliquot diluted to $100 \mathrm{ml}$. and to the standards in Nessler tubes add $5 \mathrm{ml}$. of the acid zirconium alizarin reagent from a volumetric pipette. Mix thor ughly and compare the sample and standards after one hour.

$$
\text { Calculation: } \mathrm{mg} \cdot / \text { litre fluoride }=\frac{\mathrm{mg} . \mathrm{F} \times 1,000}{\mathrm{ml} \text {. sample }}
$$

We are grateful to Dr. Anarjit Singh and Dr. I. D. Singh for guidance and facilities for this investigation. The project was partly financed by the Indian Council of Medical Research, whose help we wish to acknowledge. We are also thankful to the Director of Health Services, Punjab, and the Principal, Medical College, Patiala, for providing the transport arrangements in connexion with epidemiological surveys.

\section{REFERENCES}

Leone, N. C., et al. (1954). Publ. Hlth Rep. (Wash.), 69, 925.

Marier, J. R., Rose, D., and Boulet, M. (1963). Arch. environm. Hlth, 6, 664 .

Singh, A., and Jolly, S. S. (1961). Quart. F. Med., 30, 357.

Singh, A., Jolly, S. S., and Bansal, B. C. (1961). Lancet, 1, 197.

Singh, A., Vazirani, S. J., Jolly, S. S., and Bansal, B. C. (1962a).

Singh, A., Dass, R., Hayreh, S. S., and Jolly, S. S. (1962b). f. Bone ft Surg., 44B, 806.

Singh, A., Jolly; S. S., Bansal, B. C., and Mathur, C. C. (1963). Medicine (Baltimore), 42, 229.

Soriano, M., and Manchón, F. (1966). Radiology, 87, 1089.

Srikantia, S. G., and Siddiqui, A. H. (1965). Clin. Sci., 28, 477. 